\title{
Influencing Factors of College Student's willingness to be a Candidate of Grassroot Employment Project in China
}

\author{
Case Study of the Selected College Student Village Official in Shandong Province
}

\author{
Shuai WANG ${ }^{1}$ Masaya NAKATSUKA ${ }^{1}$ Shinji TAKADA ${ }^{1 *}$
}

\begin{abstract}
Less developed rural China has been suffering from aging cadres for decades, while college graduates are facing serious employment pressure. Based on this situation, the Shandong provincial government initiated the Selected College Student Village Officials (SCSVO) project, establishing a labour circulation system between rural and urban areas for college students. However, the number of SCSVO students is growing extremely slowly, and there is a demand for more participants. Therefore, this study clarifies the key factors that influence college students' willingness to be candidates for SCSVO. This research highlights the target characteristics of potential SCSVO candidates and provides a direction for the further development of the current SCSVO project. It applies a binary logistic regression on original data collected through questionnaires and interviews. The results reveal that (1) $37 \%$ of the respondents are willing to join the SCSVO. (2) Students with the following objective factors are more likely to join the SCSVO: younger, male, majoring in education/agronomy/medicine, personal positive impression towards rural areas, cultural-difference tolerance, and consideration of parental attitudes; these factors have significant effects on students' willingness to join. (3) For the further development of the SCSVO project, the government and SCSVO-related organisations should further disseminate the attractiveness of rural locations, such as the low-stress working conditions and natural environment.
\end{abstract}

Keywords : Grassroot Employment Projects, Selected College Student Village Official, College Student, Logistic Regression, China

\section{INTRODUCTION}

Less-developed rural China has been suffering from aging cadres for decades, while college graduates are facing serious employment pressure. Referring to Article 26 of the Regulations on the Work of Rural Grassroot Organisations of the Communist Party of China, 'cultivating village-level successors' has already been promoted into a compulsory regulation for dealing with the issue of aging cadres ${ }^{\text {note } 1)}$. On the other hand, as shown in the 2020 Chinese University Student Employment Report, during 2015-2019, the employment rate of the total college graduates decreased from $92.6 \%$ to $91 \%$, while the total number of college graduates in China has increased from 7.49 to 8.34 million.

To address these challenges, multiple Grassroot Employment Projects have been initiated by the national central government to encourage college graduates to work in rural areas. These projects aim at eliminating the rural human resource shortage in governmental agencies, village committees, village Communist Party branches (governmental autonomous institutions in village-level areas), and educational institutions. They also encourage college graduates to start businesses and to lead rural socio-economic development. Currently, the proj- ects mainly include the following: 1) College Student Volunteer Service Western Program (CSVSW) from 2003, which places college students in national service agencies and clinics as volunteers (with limited payment and living expenses from the government) in seriously poverty-stricken areas of western China. 2) The Three Supports and One Assistance project (TSOA) from 2006, which is specifically for educational, agricultural (water conservancy), and medical support and poverty alleviation services for less-developed rural locations. 3) The Special Post Teacher (SPT) from 2006, which is for primary and secondary school teachers in areas of serious poverty in central and western China. 4) The College Student Village Official (CSVO) from 2008, which places college graduates into the village-level Communist Party branch and village committee, working as assistants to the village party secretary or the head of the village committee. Since CSVO students are relatively easier to access (they exist in almost all provinces in China), this research focuses on the CSVO project.

Due to provincial autonomy, CSVO management in the province can be different from that of the central government. Recently, some provinces have attempted to merge the Selected Graduates Project (SG), which was designed to cultivate

'Graduate School of Agricultural Science, Kobe University

Corresponding Author ${ }^{*}$ : takada@gold.kobe-u.ac.jp 
governmental cadres in 1965 by sending Communist Party members to work in rural areas, into the CSVO project and refer to it as the Selected College Student Village Officials $(\mathrm{SCSVO})^{\text {note 2)}}$. Shandong Province, which is the focus of this study, has also combined SG with CSVO since 2013, and the whole process has three steps for graduates: application and examination, serving CSVO contract for two years in rural areas, and being transferred into SG after an examination. Therefore, students that complete their contracts leave the position, opening it for newcomers, and a circulating system between rural and urban areas occurs. Different from the CSVO before 2013, under which the CSVO students were just contract workers, SCSVO students are now official civil servants. Moreover, since 2016, the National Civil Service Examination in China saves $10 \%$ of vacancies for the applicants who have completed the Grassroot Employment Project, especially for SCSVO students ${ }^{1)}$.

However, $\mathrm{Fu}^{2)}$ points out that due to their higher quality of life and higher salaries, college students prefer to work in cities. Therefore, as a historical agricultural province, Shandong Province needs many young labourers to work in rural villages, and the current situation cannot meet its demand ${ }^{3)}$. According to the 2016-2017 CSVO report, between 2008 and 2017, there were $372,000 \mathrm{CSVO}$ and SCSVO across China, which is still far behind the goal of $530,000^{\text {note } 3)}$, and only $2 \%-4 \%$ of college graduates choose to work in rural areas through the Grassroot Employment Projects ${ }^{4)}$.

Therefore, this research determines the key factors that influence college students' willingness to join SCSVO, which not only contributes to highlighting the target characteristics as potential SCSVO candidates but also contributes to clarifying the development direction of the current SCSVO project.

\section{2 . RESEARCH METHOD}

\subsection{Influencing factors}

The factors tested in this study, including their data type, value, mean, and standard deviation (SD) are reported in Table 1. Since few studies focus specifically on this topic, we refer to research on 'the development of SCSVO project' and 'participants' evaluation of SCSVO'. On the other hand, since SCSVO is a rural-located position aimed at college students, research on both 'preference for working location' and 'rural working motivation' are also reviewed.

$x 1$ to $x 6$ : Zhu and Wang ${ }^{4)}$ applied questionnaire research in Jiangxi Province to examine the influencing factors of under- graduates' desire to be SCSVO candidates. A total of 19 factors were tested, and the capacity for taking pains (including the pains from both manual labour and emotional shocks), parents' attitude, and willingness towards SCSVO job showed significant effects. However, referring to Shao's ${ }^{5)}$ logistic research on rural-hukou students' willingness to work in a hometown in Fujian Province, the current study is limited because hukou $^{\text {note } 4)}$, only child or not, education degree, and college major are not tested, which are statistically significant factors in the aforementioned study.

$x 7$ : Huang ${ }^{6}$ examines the family's influence on undergraduates' employment and suggests that family members' living location impacts educational resources and opportunities for students. A rural located family usually offers farming or agricultural-related knowledge, and the longer they stay in rural areas, the higher the willingness to consider agricultural employment, while urban families are unlikely to provide agricultural-related information

$x 8$ : As a type of social activity, a part-time job is widely mentioned in previous research. Carney, Mcneish and Mccoll $^{7)}$ suggest that part-time job experience has a significant effect on a student's preference. They argue that a part-time job helps students to be independent and adventurous, to understand the value of money and the difficulties during making it, and determine the working situation they prefer.

$x 9, x 10, x 11$ : Wang and $\mathrm{Yu}^{8}$ indicate that when choosing a job, most college graduates care more about the opportunity for further promotion and self-satisfaction, not salary. Furthermore, SCSVO regulation has clearly illustrated that even when students are given bonuses, such as living allowance and social insurance, their salary is in the mid-level for the local area ${ }^{9)}$. Since Shao ${ }^{5)}$ highlights that more than $40 \%$ of the respondents are not familiar with the SCSVO project at all, 'whether the respondents know about the SCSVO project' should be assured during data collection.

x12, x13: Qian and $\mathrm{Lu}^{10)}$ suggest that the relaxing natural environment, less-stressful work, and low-cost living conditions are usually key attractions of rural-located employment, and 'college graduates cannot adapt to rural living' can be answered with the concepts of 'embedment' and 'fusion', which means that the SCSVO students are embedded into the village with limited local information, especially in terms of cultural differences (mainly local language/dialect). Additionally, mandarin is widely spoken in cities, but many rural villagers cannot speak it fluently due to limited education resources, and communication may be difficult. 
Table 1 Definition of the research variables, data type, and values

\begin{tabular}{|c|c|c|c|c|}
\hline Variable & Data type & Value & Mean & SD \\
\hline$y$. Willing to join SCSVO & Binary & $1=$ Yes, $0=$ No & 0.370 & 0.484 \\
\hline$x 1$. Gender & Binary & $1=$ Male, $0=$ Female & 0.374 & 0.485 \\
\hline$x 2$. Hukou & Binary & $1=$ Rural, $0=$ Urban & 0.192 & 0.395 \\
\hline$x 3$. Only child & Binary & $1=$ Yes, $0=$ No & 0.644 & 0.480 \\
\hline$x 4$. Education degree & $\begin{array}{l}\text { Category } \\
\qquad \begin{array}{r}1= \\
2= \\
3=\end{array}\end{array}$ & $\begin{array}{l}\text { Undergraduate } \\
\text { Graduate master } \\
\text { Graduate } \mathrm{PhD}\end{array}$ & $\begin{array}{l}0.673 \\
0.263 \\
0.064\end{array}$ & $\begin{array}{l}0.470 \\
0.441 \\
0.245\end{array}$ \\
\hline$x 5$. Subject of study & $\begin{array}{r}\text { Category } \\
1= \\
2= \\
3= \\
4= \\
5= \\
6= \\
7= \\
8= \\
9= \\
10= \\
11= \\
12= \\
13=\end{array}$ & $\begin{array}{l}\text { philosophy } \\
\text { economics } \\
\text { Law } \\
\text { education } \\
\text { literature } \\
\text { history } \\
\text { sciences } \\
\text { engineering } \\
\text { agronomy } \\
\text { medicine } \\
\text { management } \\
\text { arts } \\
\text { military }\end{array}$ & $\begin{array}{l}0.007 \\
0.313 \\
0.050 \\
0.068 \\
0.060 \\
0.004 \\
0.103 \\
0.174 \\
0.036 \\
0.028 \\
0.089 \\
0.064 \\
0.004\end{array}$ & $\begin{array}{l}0.084 \\
0.465 \\
0.218 \\
0.252 \\
0.239 \\
0.060 \\
0.305 \\
0.380 \\
0.186 \\
0.167 \\
0.285 \\
0.245 \\
0.060\end{array}$ \\
\hline$x 6$. Age & Continuous & As it is & 23.416 & 2.677 \\
\hline$x 7$. Rural living experience (years) & Continuous & Between 0 and 50 & 5.395 & 2.407 \\
\hline$x 8$. Part-time job experience (years) & Continuous & & 1.488 & 1.913 \\
\hline$x 9$. Further promotion opportunity is the most important thing when shifting jobs. & Grade & $1=$ Strongly disagree, & 3.772 & 0.823 \\
\hline$x 10$. Self-satisfaction is important to you during employment. & Grade & $2=$ Disagree & 3.996 & 0.725 \\
\hline$x 11$. Middle-income in the local area is enough for me. & Grade & $3=$ Neutral, & 3.203 & 1.031 \\
\hline$x 12$. You can accept working in rural villages. & Grade & $4=$ Agree & 3.039 & 1.040 \\
\hline$x 13$. Cultural differences (mainly local language) are unacceptable when shifting jobs. & Grade & $5=$ Strongly agree & 3.281 & 1.067 \\
\hline$x 14$. Attitudes of parents or family are important when looking for a job. & Grade & & 2.815 & 1.046 \\
\hline$x 15$. The social network is important while looking for a new place for a job. & Grade & & 3.559 & 0.881 \\
\hline x16. Local amenities and development level are important when shifting jobs to a new place. & Grade & & 3.733 & 0.896 \\
\hline
\end{tabular}

14: Zhu and Wang ${ }^{4)}$ proved that attitude of family has a significant impact. They concluded that children usually listen to their parents even after they grow up. Moreover, their findings also illustrate that the economic situation of the family shows no statistical significance.

$x 15$ : Pisman et al. ${ }^{11)}$ claim that social networks are not drivers of migration. However, Wang and $\mathrm{Yu}^{8)}$ highlight that Chinese college students usually consider cultivating personal social networks during employment, because they believe that it can help them access information and resources more easily.

x16: Local amenities are another factor when students are looking for employment. Wang and $\mathrm{Yu}^{8)}$ revealed that college students prefer developed and convenient lifestyles in cities. On the contrary, Feijten et al. ${ }^{12)}$ argue that people are willing to move to rural areas if there is an 'acceptable quality of life' and well-established outdoor recreation facilities, with a better natural environment than cities.

\subsection{Data collection \& analysis}

This study utilised both questionnaires and open-ended interviews; the former aims at statistical evidence, and the latter focuses on determining respondents' personal opinions and explanations. After the questionnaire data were collected, the general features of the respondents were identified, and logistic regression was applied to determine the statistically significant factors in the questionnaires. Results from the interviews are used to identify the keywords and reasons from the respondents, and the results of logistic regression can determine which factors are statistically significant. Questionnaires and interviews focused on identical questions from $x 9$ to $x 16$. Additionally, interviews further aim at 'why and how', such as 'why do you care about self-satisfaction during employment?' and 'how do you feel when facing cultural differences?'.

Most researchers apply only one research method, and they usually prepare clear content for respondents to choose ${ }^{4), 5)}$. In contrast, the current study applied open-ended interviews and interviewees could answer freely. Furthermore, simple and easily understandable questions are applied to minimise the impact of 'low standardised answers'. Therefore, more accurate and complete data can be obtained ${ }^{13)}$.

Data were collected at Binzhou University (BZU), Shandong Province, in June 2018. The BZU's annual employment 
rate of graduates is stable at $97.5 \%$ with 19,500 full-time students, which is one of the highest employment rates in Shandong. With BZU's permission, students in certain classrooms were able to participate in this research during classes; they were on optional courses. Almost 400 students participated. Questionnaires were distributed and interviews were conducted. We started with a brief introduction of the SCSVO project, including its working process and welfare (considering that someone has never heard about SCSVO) and a question and answer section (eliminating the issue of misunderstanding of the questions). We then distributed and collected the questionnaires by hand. In addition, since some of the students had already found jobs or further study opportunities, they did not participate in this research. After the questionnaires were collected, the respondents were randomly invited to participate in another open-ended face-to-face interview lasting 10 minutes. In addition, confidentiality and anonymity of the respondents were ensured.

Considering that it is relatively easier to assure the regression formula, a binary logistic regression was applied for the statistical analysis. In equation (1), $\beta$ is the parameter used to estimate the conditional probability of the outcome given the observed independent variables $x$, where $f$ is the logistic density function, and the maximum likelihood method is applied. In equation (2), the dependent variable $y$ is the willingness to join SCSVO, $x$ is the 27 variables (including the factor variables generated from different categories), and $\beta$ is the coefficient to estimate. The calculation was performed using Stata IC 16.

$$
\begin{aligned}
& \operatorname{Pr}\left\{y=1 \mid x_{i} ; \beta\right\}=f\left(x_{i} ; \beta\right)=\frac{1}{1+e^{-x_{i}^{\prime} \beta}}=\frac{e^{-x_{i}^{\prime} \beta}}{1+e^{-x_{i}^{\prime} \beta}} \\
& L(\beta \mid y ; X)=\prod_{i} f\left(x_{i} ; \beta\right)^{y_{i}}\left(1-f\left(x_{i} ; \beta\right)\right)^{1-y_{i}}
\end{aligned}
$$

\section{RESULTS}

\subsection{Questionnaire results}

A total of 300 questionnaires were sent out and 281 valid questionnaires were collected. The detailed description of the results is presented below.

$y$ : A total of 177 of the respondents $(63.0 \%)$ chose $0=\mathrm{No}$ and the remaining $104(37.0 \%)$ chose $1=$ Yes, which means that most were not willing to join SCSVO. $x 1: 176(62.6 \%)$ were female, 105 (37.4\%) were male. $x 2: 227(80.8 \%)$ had an urban hukou, 54 (19.2\%) had a rural hukou. x3: 181 (64.4\%) were only children, 100 (35.6\%) were not. x4: 189 (67.3\%)
Table 2 Questionnaire data on $x 9$ to $x 16$

\begin{tabular}{c|c|c|c|c|c}
\hline \hline & $\begin{array}{c}1=\text { Strongly } \\
\text { disagree }\end{array}$ & $2=$ Disagree & $3=$ Neutral & $4=$ Agree & $\begin{array}{c}5=\text { Strongly } \\
\text { agree }\end{array}$ \\
\hline$x 9$ & $\begin{array}{c}5 \\
(1.8 \%)\end{array}$ & $\begin{array}{c}18 \\
(6.4 \%)\end{array}$ & $\begin{array}{c}50 \\
(17.8 \%)\end{array}$ & $\begin{array}{c}171 \\
(60.9 \%)\end{array}$ & $\begin{array}{c}37 \\
(13.2 \%)\end{array}$ \\
\hline$x 10$ & 3 & 11 & 23 & 191 & 53 \\
& $(1.1 \%)$ & $(3.9 \%)$ & $(8.2 \%)$ & $(68.0 \%)$ & $(18.9 \%)$ \\
\hline \multirow{2}{*}{$x 11$} & 12 & 80 & 38 & 141 & 10 \\
& $(4.3 \%)$ & $(28.5 \%)$ & $(13.5 \%)$ & $(50.2 \%)$ & $(3.6 \%)$ \\
\hline \multirow{2}{*}{$x 12$} & 26 & 59 & 83 & 104 & 9 \\
& $(9.3 \%)$ & $(21.0 \%)$ & $(29.5 \%)$ & $(37.0 \%)$ & $(3.2 \%)$ \\
\hline$x 13$ & 11 & 72 & 51 & 121 & 26 \\
& $(3.9 \%)$ & $(25.6 \%)$ & $(18.1 \%)$ & $(43.1 \%)$ & $(9.3 \%)$ \\
\hline$x 14$ & 26 & 103 & 52 & 97 & 3 \\
& $(9.3 \%)$ & $(36.7 \%)$ & $(18.5 \%)$ & $(34.5 \%)$ & $(1.1 \%)$ \\
\hline \multirow{2}{*}{$x 15$} & 3 & 40 & 60 & 153 & 125 \\
& $(1.1 \%)$ & $(14.2 \%)$ & $(21.4 \%)$ & $(54.4 \%)$ & $(44.5 \%)$ \\
\hline$x 16$ & 4 & 34 & 34 & 170 & 39 \\
& $(1.4 \%)$ & $(12.1 \%)$ & $(12.1 \%)$ & $(60.5 \%)$ & $(13.9 \%)$ \\
\hline
\end{tabular}

were undergraduate students, 74 (26.3\%) were masters, and the remaining $18(6.4 \%)$ were $\mathrm{PhD}$ students. $x 5$ : Based on the number of people, majors were: $2=$ economics $(31.3 \%), 8=$ engineering $(17.4 \%), 7=$ sciences $(10.3 \%), 11=$ management $(8.9 \%), 4=$ education $(6.8 \%), 12=\operatorname{arts}(6.4 \%), 5=$ literature $(6.0 \%), 3=$ law $(5.0 \%), 9=$ agronomy $(3.6 \%), 10=$ medicine $(2.8 \%), 1=$ philosophy $(0.7 \%), 6=$ history $(0.4 \%)$, and $13=$ military (0.4\%). x6: $101(35.9 \%)$ were $24-26$ years old, 100 (35.6\%) are 21-23 years old, 43 (15.3\%) are 27-29 years old, years, and 37 (13.2\%) were 18-20 years old. x7: 143 (50.9\%) did not have any rural living experience, 84 (29.9\%) had 1-3 years' experience, $30(10.7 \%)$ had $4-6$ years, 9 (3.2\%) had 7-9 years, and 15 (5.3\%) had 10-12 years experience. $x 8: 117$ $(41.6 \%)$ did not have any part-time job experience, 132 (47.0\%) had 1-3 years' experience, $26(9.3 \%)$ had 4-6 years, $3(1.1 \%)$ had $7-9$ years, and $3(1.1 \%)$ had $10-12$ years.

Referring to $x 9$ to $x 16$, the detailed questionnaire data is reported in Table 2. Most respondents received more agreed grades (including $4=$ Agree and $5=$ Strongly agree) than disputed grades (including $1=$ Strongly disagree and $2=$ Disagree), except $x 14$. This means that the respondents agreed with most of the statements. For example, since Grades 4 and 5 are considered as agreement, $74 \%$ of the respondents said that further promotion opportunities are important in $x 9$. Based on the numbers of Grade 3, Neutral, $x 12$ is the highest among the eight factors (83), while $x 10$ is the lowest (23). This means that respondents show relatively more undefined attitudes on $x 12$ than $x 10$.

\subsection{Logistic regression results}

Based on the p-values in Table 3, only $x 1$ and $x 5$ (compared 
Table 3 Results of Logistic Regression

\begin{tabular}{|c|c|c|c|c|c|c|c|c|}
\hline Varial & & Coef. & Robust se & z-stat & $p$-value & (95\% Conf. & Interval) & Marginal Effect \\
\hline$x 1$ & & 0.744 & 0.366 & 2.030 & $0.042 * *$ & 0.026 & 1.462 & 0.146 \\
\hline$x^{2}$ & & -0.174 & 0.725 & -0.240 & 0.811 & -1.594 & 1.247 & -0.034 \\
\hline$x 3$ & & -0.539 & 0.446 & -1.210 & 0.227 & -1.412 & 0.335 & -0.106 \\
\hline \multirow[t]{3}{*}{$x 4$} & undergraduate & & & & (base group) & & & \\
\hline & graduate master & -0.395 & 0.409 & -0.970 & 0.334 & -1.197 & 0.407 & -0.077 \\
\hline & graduate $\mathrm{PhD}$ & -0.791 & 0.944 & -0.840 & 0.402 & -2.642 & 1.059 & -0.155 \\
\hline \multirow[t]{9}{*}{$x 5$} & economics & 0.781 & 0.639 & 1.220 & 0.222 & -0.472 & 2.034 & 0.153 \\
\hline & law & -0.368 & 1.027 & -0.360 & 0.720 & -2.380 & 1.645 & -0.072 \\
\hline & education & 1.541 & 0.780 & 1.970 & $0.048 * *$ & 0.012 & 3.070 & 0.302 \\
\hline & literature & 0.603 & 1.011 & 0.600 & 0.551 & -1.378 & 2.585 & 0.118 \\
\hline & sciences & 0.605 & 0.722 & 0.840 & 0.402 & -0.809 & 2.020 & 0.119 \\
\hline & engineering & 0.239 & 0.703 & 0.340 & 0.734 & -1.139 & 1.617 & 0.047 \\
\hline & agronomy & 2.625 & 1.090 & 2.410 & $0.016 * *$ & 0.489 & 4.761 & 0.515 \\
\hline & medicine & 1.834 & 1.038 & 1.770 & $0.077 *$ & -0.200 & 3.868 & 0.360 \\
\hline & $\begin{array}{l}\text { management } \\
\text { arts }\end{array}$ & 1.176 & 0.788 & 1.490 & $\begin{array}{c}0.136 \\
\text { (base group) }\end{array}$ & -0.369 & 2.721 & 0.231 \\
\hline$x 6$ & & -0.085 & 0.032 & -2.680 & $0.007 * * *$ & -0.147 & -0.023 & -0.017 \\
\hline$x 7$ & & -0.024 & 0.033 & -0.710 & 0.480 & -0.089 & 0.042 & -0.005 \\
\hline$x 8$ & & 0.059 & 0.119 & 0.490 & 0.623 & -0.175 & 0.292 & 0.011 \\
\hline$x 9$ & & -0.070 & 0.256 & -0.270 & 0.785 & -0.572 & 0.432 & -0.014 \\
\hline$x 10$ & & 0.132 & 0.231 & 0.570 & 0.566 & -0.320 & 0.584 & 0.026 \\
\hline$x 11$ & & 0.028 & 0.176 & 0.160 & 0.873 & -0.316 & 0.372 & 0.005 \\
\hline$x 12$ & & 1.638 & 0.306 & 5.350 & 0.000 *** & 1.038 & 2.239 & 0.321 \\
\hline$x 13$ & & -0.557 & 0.179 & -3.110 & $0.002 * * *$ & -0.907 & -0.206 & -0.109 \\
\hline$x 14$ & & 0.385 & 0.184 & 2.090 & $0.036 * *$ & 0.025 & 0.746 & 0.076 \\
\hline$x 15$ & & 0.093 & 0.205 & 0.450 & 0.652 & -0.310 & 0.495 & 0.018 \\
\hline$x 16$ & & -0.170 & 0.230 & -0.740 & 0.458 & -0.621 & 0.280 & -0.033 \\
\hline Constant & & -3.484 & 1.806 & -1.930 & $0.054 *$ & -7.022 & 0.055 & \\
\hline$N$ & & & 277 & & & & & \\
\hline \multicolumn{2}{|c|}{ Pseudo R2 } & & 0.370 & & & & & \\
\hline \multicolumn{2}{|c|}{ Log pseudolikelihood } & & -114.873 & & & & & \\
\hline
\end{tabular}

with arts, only education, agronomy, and medicine are statistically significant), $x 6, x 12, x 13$, and $x 14$ are statistically significant. $x 12, x 13$, and $x 6$ are significant at the $1 \%$ level. $x 14$ and $x 1$ are significant at the $5 \%$ level. In particular, four of the questionnaires were not valid for the regression test because the results were predictable; only 2,1 , and 1 students were majoring in philosophy, history, and military, respectively. Referring to $x 5$, even though the three significant sub-variables show extremely high coefficients, it does not mean that $x 5$ has the strongest influence because the total sample of the sub-variables is less than 277. Therefore, we discuss the majors in $x 5$ separately. Regarding the three statistically significant subjects in $x 5$, agronomy and education are significant at the $5 \%$ level, and medicine at the $10 \%$ level. Since the larger absolute value of marginal effect represents the larger influence on $y$ and $+/-$ of the coefficient indicate positive/negative effects, the results in Table 2 clarify "how much the variable $x$ can affect the variable $y^{\prime}$. Based on the absolute value of marginal effects, $x 12$ shows the greatest effect, followed by $x 1$, $x 13, x 14$, and $x 6$ (which is extremely weak). In $x 5$, agronomy shows the largest effect and is followed by medicine and education.

\subsection{Interview results}

A total of 62 of the 281 questionnaire respondents were interviewed. As shown in Table 4, their reasons were divided as follows: Disagree (respondents who answered 1=Strongly Disagree or $2=$ Disagree in the questionnaire), neutral ( $3=$ neutral in the questionnaire), and agree ( $4=$ Agree or $5=$ Strongly Agree in the questionnaire).

Most interviewees gave similar answers (38 of the 62 respondents agree with $x 9$, etc.), which suggests that college students have the same aspirations for employment, except $x 14$ (23 agree and 26 disagree). In addition, some questions appeared that 'one interviewee with multiple reasons', for example, one interviewee, who shows Disagree attitude on $x 11$, choose both 'Money is never enough' and 'I deserve a higher salary'. It shows that among the 'one interviewee with multiple reasons' factors, students have multi-dimensional demands. It cannot be ignored that some reasons have been repeatedly mentioned in multiple questions (including high salary, pressureless working conditions, parents' attitude, and stable employment), and these factors can be influenced by each other (e.g. parents' influence can also affect $x 9, x 12$, and $x 13$ ). We present a detailed discussion in section 4 . 
Table 4 Interview results: Key reasons for the answers

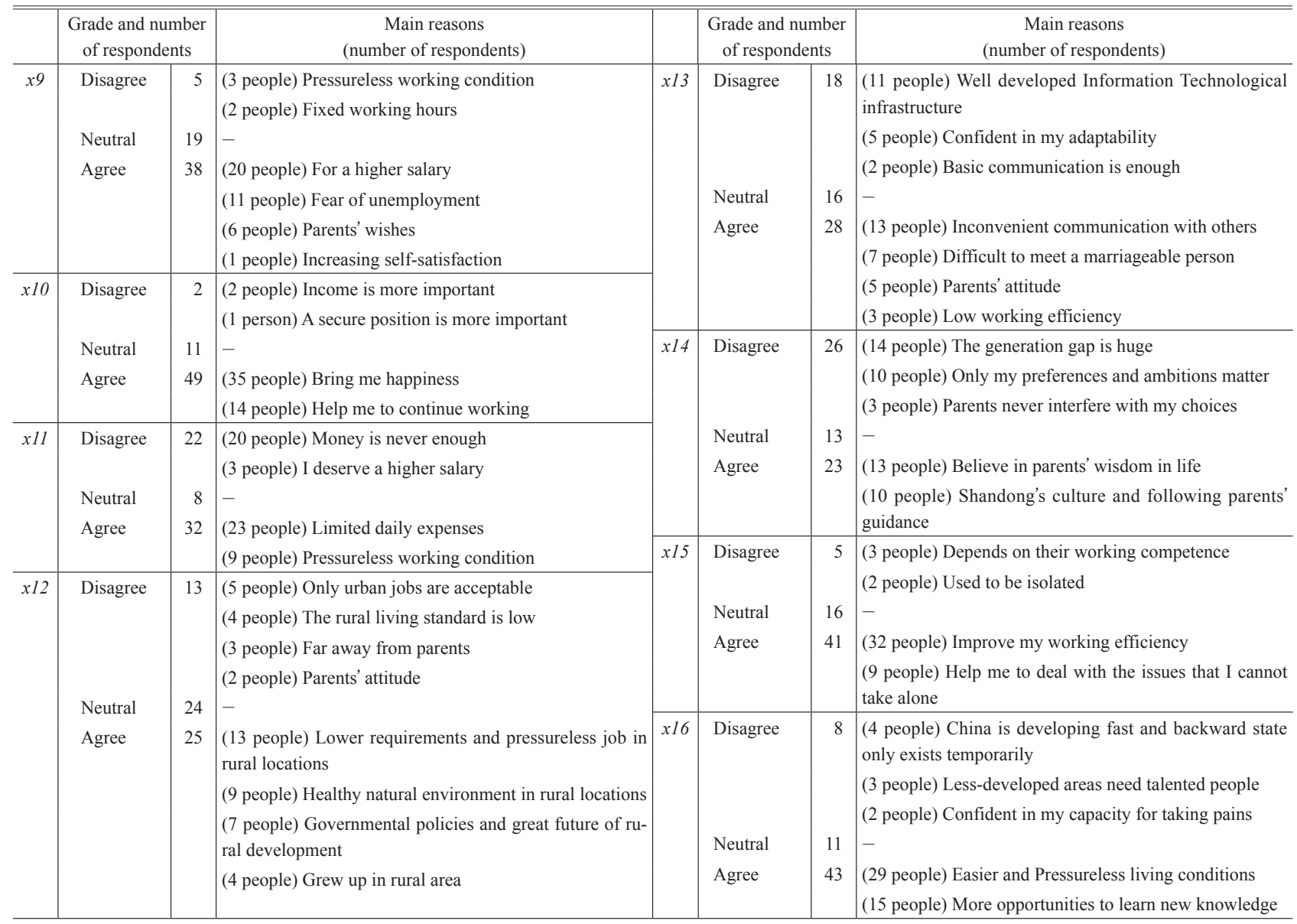

Note: In the 'main reason' part, because it is an open-ended answer, an interviewee may mention multiple reasons.

\section{DISCUSSION}

\subsection{Statistically significant factors}

$x 1$. In contrast to Zhu and $\mathrm{Wang}^{4)}$ and Shao ${ }^{5)}$, gender significantly influences desire, and male students are more interested in being an SCSVO candidate than females. Based on the interview survey, interviewees show a subjective belief that rural living is more laborious than an office job in cities (Disagree reasons, 9 respondents). Female students may be more concerned about the laborious nature of rural living. On the other hand, because the locations are different, the diverse results can also be explained by regional variations.

$x 5$. The possible reason for the statistical significance is that students in these three majors can receive relatively more knowledge and frontier news on rural development during their study period ${ }^{4}$. On the other hand, the government has initiated several bonus initiatives to encourage agricultural and medical college students to work in rural areas, such as tuition fee reduction, exemption or refund, and student loan compensation $^{8)}$. On the contrary, referring to the Disagree response 'Money is never enough' in $x 11$, interviewees men- tioned that the tuition fee refund is not sufficiently attractive to motivate them to work in rural locations. Specifically, they mention that the tuition fee for an undergraduate student is about 6,000 RMB a year, while a job in urban areas can bring an average 31,597 RMB (from China Statistical Yearbook 2019, an average of both rural and urban areas). Therefore, they prefer jobs in urban areas for higher income rather than working in rural areas with refunded tuition fees.

$x 6$. Unfortunately, since none of the questions focused on the influence of age and a limited amount of information can be determined, the reason for its significance cannot be perfectly answered. Statistically, Zhang ${ }^{3)}$, who investigated the factors that affect the intention to stay in SCSVO, suggests that the educational environment is influential. In other words, as age increases, respondents' intention to join SCSVO decreases because they consider their children's educational environment and family-related issues. As evidence, the marriage issue was repeatedly mentioned during interviews (7 respondents, $x 13$ 's Agree reasons).

12: A total of $40.2 \%$ of the questionnaire respondents are willing to accept rural jobs, and this result is similar to that of 
Wang $^{13)}$, who argues that students prefer urban-located jobs for two reasons: 1) they have adapted to the modern and convenient lifestyle during their years of study, and 2) they usually believe that urban-located jobs offer a higher salary. Referring to the reasons, it should be emphasised that 'rural locations are usually far away from industrial facilities and the natural environment is well-protected' was repeatedly mentioned by nine people for Agree reasons, while seven believe that the rural areas will be better developed with a series of governmental policies. It indicates a diverse finding that, when shifting jobs, students also consider the natural environment and health issues along with high salary.

$x 13$. As shown in Table 2, 52.4\% of the respondents agreed with the expression in the questionnaires, and the results of the logistic regression analysis indicates that both the coefficient and the marginal effect were negative. This means that more than half of respondents cannot accept cultural differences (mainly local language) when looking for employment in a new place. Referring to these reasons, interviewees agree that language differences increase inconvenient communication with others and decrease work efficiency. Moreover, interviewees were worried that cultural difference (mainly language difference) is a serious problem during marriage, and the SCSVO job cannot be an opportunity to meet a marriageable person. However, on the contrary, it should be noted that 11 interviewees mentioned that rural development is unpredictably fast, and the infrastructure is no longer incompatible with cities. Additionally, thanks to the widespread 4G (or 5G) base stations throughout China ${ }^{\text {note 5) }}$, smartphones and computers can help communication. Therefore, it can be concluded that even though cultural differences (mainly local language) have a statistical effect, there are methods to decrease its influence. This finding is in contrast to Qian and $\mathrm{Lu}^{10)}$, who argue that students should adapt to the local cultural environment rather than maintain their modern lifestyle. In other words, rural areas are no longer entirely less-developed areas; instead, rural areas can be ready for more kinds of industries, such as information technology (IT), than agriculture-related areas.

$x$ 14: Unsurprisingly, parents' attitudes had a significant influence on the regression results. Referring to the reasons, 13 interviewees believed in parents' decisions due to their wisdom and experience, and 10 mentioned that Shandong people share a long-historical culture in which family and parents are always irreplaceable. Compared with Zhu and Wang ${ }^{4}$, who only explain blood relations, it enriches the bonding with both rational (rich experience) and region-cultural (long-historical culture in Shandong) aspects. However, it cannot be ignored that students show significant signs of independent thinking, which can be proved by the data in Table 2; in the questionnaires, $47 \%$ disagreed vs. $35.6 \%$ agreed. This finding is similar to Shen and Wang ${ }^{14)}$, who suggest that, from the perspective of developmental psychology, college students are facing the stage of emotional separation and individualisation.

\subsection{Statistically insignificant factors}

It should be emphasised that most factors share a similarity in that more than half of respondents show the same attitude in the questionnaire (agree with the statements of the factors), including the insignificant ones of $x 2, x 3, x 7, x 8, x 9, x 10, x 11$, $x 15$, and $x 16$. In other words, there are limited samples of disagreed attitudes, and the samples are not equal. Therefore, the statistical insignificance in logistic regression can be explained by the fact that the collected data are not suitable for fully testing the factors. For example, for $x 8$, a significant proportion of the respondents (117 of 281) of respondents had no part-time job experience, while many others (132) had only 1-3 years' experience; there are insufficient samples in other periods classification for statistical analysis.

On the other hand, the insignificances can be explained by the opposite opinions during interviews on the same factor (for a certain factor, the most repeatedly mentioned disagree and agree reasons have a similar number of interviewees), especially $x 11, x 13$, and $x 14$. For example, $x 11,20$ interviewees mention that 'money is never enough, therefore, middle-income is not enough' as a disagree reason and 23 mention that 'since they spend limited daily expenses, middle-income is enough' as an agree reason. Therefore, it can be explained that these two reasons simultaneously exist among the interviewees, and none seriously affect interviewees' willingness to join SCSVO.

\section{CONCLUSION}

Due to the imperfections in previous research, this study applied modified research questions and research methods, and revealed different results. Students with the following factors are more likely to join SCSVO: younger, male, majoring in education/agronomy/medicine, with positive impression towards rural areas, cultural-difference tolerance, and parents' agreement. In addition, our results revealed different statistically significant factors based on participants responses and 
these differed from previous research. On the other hand, since most of the respondents and interviewees agree with statements of the insignificant factors, it can be determined that these can show the general condition of the graduates. For the further development of the SCSVO project, we suggest that governments pay more attention to disseminating the attractiveness and the richness of life in rural locations, such as stable and low-stress working conditions, natural environment, well-established infrastructure, and the future of rural development. In addition, to deal with cultural differences, to know more about the SCSVO-hosting regions and focus on developing a local understanding of the SCSVO system and local counterparts. Furthermore, to bring salary levels in line with those in cities, but this may not be realistic when considering the financial situation in rural regions, instead, further improving the preferential treatment for the SCSVOs and promoting the understanding that working in rural areas can be an effective career for college graduates (such as bonuses in postgraduate and civil service examinations, recruitment into the civil service). It will also be helpful to address family/parents' outdated perceptions of rural areas.

Referring to the limitations and shortcomings of this study, multiple-meaning concepts in the questionnaire can be further clarified and further researched, such as the preference to work in rural areas' in $x 12$ and the 'cultural differences' in $x 13$. Therefore, this research cannot perfectly answer the questions of "what kind of rural employment is the most attractive to college students?' and 'what kind of cultural differences are the most challenging for them?' Second, due to limitations of funding and time, only 62 of the 281 respondents were interviewed and only questions $x 9$ to $x 16$ were tested; thus, $x 6$ cannot be perfectly tested. For further analysis, all tested factors should be identical in both questionnaires and interviews.

\section{NOTES}

Note 1) The 'Regulations on the Work of Rural Grassroot Organizations of the Communist Party of China' was first issued by the Central Committee of the Communist Party of China in 1999. Due to the dramatic development in rural areas, it was amended in 2019. Available at: http://www.gov.cn/zhengce/content_5356764.htm

Note 2) Based on the series 'Development Report of the College Student Village Official'. As of the end of August 2020, the series includes annual reports from 2009 to 2015 and a 2016-2017 report.

Note 3) The figure ' 530,000 ' is a dynamic number. 'One CSVO per village' has been the goal since the CSVO project was established. 'Village' means an administrative village, the smallest autonomous unit in China. According to the '2020 China Public Service Industry Analysis Report', there were 533,000 administrative villages in 2019 .

Note 4) 'Hukou' is a household registration system in China, which is usually determined by the birthplace. Since 1958, it has been divided into two types: agricultural (or rural) and non-agricultural (or urban), with different management systems and different public welfare; since 2014, the Chinese government has been working on reforming this system, hoping to unite the two types.

Note 5) As of June 2019, 77.6\% of rural villages are covered by 4G base stations. Available at:

http://www.miit.gov.cn/c7696411.html, February 27, 2020.

\section{REFERENCES}

1) Notification of the National Civil Servants Examination in 2016, from the Ministry of Human Resources and Social Security, Available at <http://www.gov.cn/content_2946062.htm>, December 13, 2015.

2 ) Fu, J. J. (2010): Placing Elite in Countryside, the Path of Modern Country's Integration of Rural Society-Case Study of College Student Village Officials, Journal of Youth Research, 3, 13-23.

3 ) Zhang, W. G. (2010): Research on the College Student Village Officials and the New Countryside Construction, Economic Systems Reform, 1, 178-181.

4 ) Zhu, Z. Y. and Wang, Y. C. (2014): Evaluation on the Satisfaction and Influencing Factors of the College Student Village Official Recruitment Policy, Journal of Hunan Agricultural University (Social Science Edition), 14, No. 3, 13-19.

$5)$ Shao, Y. L. (2012): Willingness and Influencing Factors of Rural College Students to Return Hometown for Employment-Case Study in Fujian, Journal of Fujian Jiangxia University, 4, 32-37.

6 ) Huang, Z. X. (2018): Different Employment Outcomes of Undergraduate Graduates Between Urban and Rural Families, Journal of Jiangxi Normal University, Doctoral Research.

7 ) Carney, C., Mcneish, S. and Mccoll, J. (2005): The Impact of Part-Time Employment on Students' Health and Academic Performance: A Scottish Perspective, Journal of Further and Higher Education, 29, No. 4, 307-319.

8 ) Wang, Z. G. and Yu, Y. M. (2010): Employment Motivation, Satisfaction and Long-Term Development Mechanism of College Student Village Officials, China Soft Science, 6, 87-96.

9 ) Introduction of the Grassroot Employment Projects, from Ministry of Education of the People's Republic of China, Available at $<$ http://www.moe.gov.cn/t_225998.html>, December 25, 2015.

10) Qian, D. Z. and Lu, Z. Y. (2018): From 'Embedded' to 'Fused'Weakening and Optimization of College Student Village Officials Project, Journal of Sociological Research in Jiangsu, 4, 107-113.

11) Pisman, A., Allaert, G. and Lombaerde, P. (2011): Urban and Suburban Lifestyles and Residential Preferences in a Highly Urbanized Society, Belgeo, 2, No. 1-2, 89-104.

12) Feijten, P., Hooimeijer, P. and Mulder, C. H. (2008): Residential Experience and Residential Environment Choice over the Lifecourse, Urban Studies 45: 141-162.

13) Wang, H. F. (2018): Evaluation on Talents' Attraction of Cities' Cluster Where National Central City Is Located, Journal of Employment of Chinese University Students, 20, 39-46.

14) Shen, X. and Wang, K. (2019): Problems and Countermeasures of the Communication Between College Students and Their Parents, Reform and Opening, 7, 66-68.

(Received: Jul 28, 2020, Accepted: May 24, 2021) 